Check for updates

Cite this: RSC Adv., 2017, 7, 21906

Received 8th February 2017 Accepted 7th April 2017

DOI: 10.1039/c7ra01597f

rsc.li/rsc-advances

\section{Changes in molecular film metallicity with minor modifications of the constitutive quinonoid zwitterions $\dagger$}

\author{
Lucie Routaboul, (D) *a Iori Tanabe, ${ }^{\mathrm{b}}$ Juan Colon Santana, ${ }^{\mathrm{b}}$ Minghui Yuan, ${ }^{\mathrm{a}}$ \\ Alessio Ghisolfi, ${ }^{a}$ William Serrano Garcia, ${ }^{\text {b }}$ Peter A. Dowben, (D) *b Bernard Doudin (D) \\ and Pierre Braunstein (D)*a
}

\begin{abstract}
Molecular films of quinonoid zwitterions, of the general formula $\mathrm{C}_{6} \mathrm{H}_{2}(\ldots \mathrm{O})_{2}(\cdots \mathrm{NHR})_{2}$, have been shown to display electronic properties highly dependent on the nature of the $\mathrm{N}$-substituent $\mathrm{R}$ when deposited on gold substrates. The different spacing and organization of the molecules can lead to molecular films with semi-metal or dielectric behavior. With the long term goal to establish how packing effects in the solid state correlate with properties as thin films, we first attempted to identify by X-ray diffraction analysis candidate molecules showing suitable packing arrangements in the crystalline state. To this end, we have prepared a series of new functionalized, enantiopure or sterically-hindered quinonoid zwitterions and established the crystal structure of those with $\mathrm{R}=\mathrm{CH}_{2}-\mathrm{CH}_{2}-\mathrm{Ph}$ (6), $\mathrm{CH}_{2}-\mathrm{CH}_{2}-\mathrm{CH}_{2}-\mathrm{Ph}$ (7), $\mathrm{CH}_{2}-\mathrm{CH}_{2}-$ $\mathrm{CH}_{2}-\mathrm{CH}_{2}-\mathrm{Ph}$ (8), $\mathrm{CH}_{2}-\mathrm{CH}_{2}-\mathrm{CH}(\mathrm{Ph})-\mathrm{Ph}$ (9), $\mathrm{CH}\left(\mathrm{CH}_{3}\right)-\mathrm{Ph}$ (12), $\mathrm{CH}\left(\mathrm{CH}_{2}-\mathrm{CH}_{3}\right)-\mathrm{Ph}$ (13), $\mathrm{CH}_{2}-\left(\left(4-\mathrm{CH}_{3}\right)-\right.$ $\left.\mathrm{C}_{6} \mathrm{H}_{4}\right)$ (15), $\mathrm{CH}_{2}-\left(\left(4-\mathrm{NH}_{2}\right)-\mathrm{C}_{6} \mathrm{H}_{4}\right)$ (19) and $\mathrm{CH}_{2}-\mathrm{CH}_{2}-\left(\left(3,4-\left(\mathrm{OCH}_{3}\right)_{2}\right)-\mathrm{C}_{6} \mathrm{H}_{3}\right)$ (24). An analysis of the crystal packing of three molecules, 5, 13 and 15, selected as illustrative examples for comparisons, was carried out and it was unexpectedly found that these chemically very similar molecules gave rise to different packing in the bulk, with resulting thin films showing different electronic properties. Various methods have been used for the characterization of the films, such as synchrotron radiation-based FTIR spatial spectra-microscopy, which provided an anchoring map of zwitterion 15 on a patterned substrate $\left(\mathrm{Au} / \mathrm{SiO}_{2}\right)$ showing its selective anchoring on gold. This is one of the best examples of preferential anchoring of a zwitterion and the sole example of spatial localization for a quinonoid zwitterion thin film. We have also used combined photoemission and inverse photoemission spectra and the data were compared to occupied and unoccupied DFT density state calculations.
\end{abstract}

\section{Introduction}

Highly conductive organic materials are much needed in molecular electronics. So are dipolar molecules that can serve as suitable additives in organic electronics, for better charge separation and injection/collection in the case of organic semiconductor devices. ${ }^{1}$ Thus, the development of such dipolar molecules and their use to form molecular films are very attractive fields of research. By varying the structure of the organic additives, there is the potential for fine-tuning the

\footnotetext{
aniversité de Strasbourg, CNRS, CHIMIE UMR 7177, Laboratoire de Chimie de Coordination, 4 rue Blaise Pascal, 67081 Strasbourg, France. E-mail: lroutaboul@ unistra.fr; braunstein@unistra.fr

${ }^{b}$ Dept. of Physics and Astronomy, Nebraska Center for Materials and Nanoscience, University of Nebraska-Lincoln, Lincoln, NE 68588, USA.E-mail: pdowben1@unl.edu

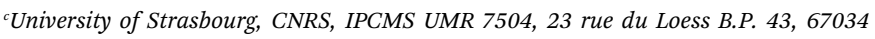
Strasbourg, France

$\dagger$ Electronic supplementary information (ESI) available. CCDC 1531545-1531553. For ESI and crystallographic data in CIF or other electronic format see DOI: $10.1039 / \mathrm{c} 7 \mathrm{ra01597f}$
}

electronic properties of the molecular film, ${ }^{2}$ and for switching its electronic properties. $^{3}$ In contrast to organometallic compounds, there are only limited examples of highly conductive organic materials, such as the charge-transfer Bechgaard salt complexes and some charge neutral quinonoid zwitterions. ${ }^{4}$ The synthesis of single compounds containing both an electron acceptor and an electron donor group is particularly attractive. The interatomic overlap of $\pi$-orbitals of polycyclic heteroarenes, the interatomic spacing, the mutual orientation of the molecules (face-to-face, edge-to-face, and so on) and the energy placement of frontier orbitals are important parameters that influence conductivity.

In this context, prior work described the formation of semimetallic self-assembled monolayers (SAMs) made from quinonoid zwitterions, of the general formula $\mathrm{C}_{6} \mathrm{H}_{2}(\cdots \mathrm{O})_{2}(\cdots \mathrm{NHR})_{2}$, deposited on conductive substrates. ${ }^{4 \boldsymbol{d}, 5}$ These "potentially antiaromatic" zwitterionic molecules (Scheme 1) have diverse applications and contain two $6 \pi$ electron sub-systems delocalized over five atoms. ${ }^{6}$ Two carbon-carbon single bonds chemically connect and electronically isolate the anionic 


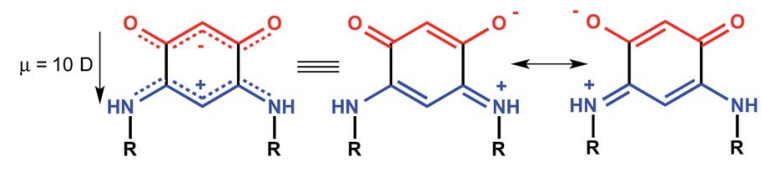

R: $\mathrm{H}(1), n \mathrm{Bu}$ (2), $\mathrm{CH}_{2}-\mathrm{CH}_{2}-\mathrm{CH}_{2}-\mathrm{SMe}(3), \mathrm{CH}_{2}-\mathrm{CH}_{2}-\mathrm{CH}_{2}-\mathrm{OMe}$ (4), $\mathrm{CH}_{2}-\mathrm{Ph}$ (5)

Scheme 1 Resonance forms of the quinonoid zwitterions investigated.

(trimethyne oxonol) and the cationic $6 \pi$ electron sub-systems (trimethyne cyanine). This feature results in a strong molecular dipole moment of around 10 Debyes.

We have previously detailed how a gold substrate can be fully covered by thin, homogeneous, and pinhole-free molecular films of well-organized zwitterionic dipoles (Scheme 2). ${ }^{5 a, b, e}$

A comparative study carried out on five zwitterionic molecules differing by the nature of the $\mathrm{R}$ substituent attached to the $\mathrm{N}$ atoms of the quinonoid zwitterion has allowed us to determine structural features relevant to the electronic properties of the films. ${ }^{5 e}$ Notably, we found that the molecular film prepared from the benzylic zwitterion 5 (Scheme 1) on gold exhibits electronic properties close to semi-metallic. ${ }^{4 d, 5 e}$

It behooves us to further examine to what extent changing the $\mathrm{R}$ substituent can modify the electronic properties of the film. More precisely, we would like to take advantage of the steric hindrance and intermolecular interactions involving the $\mathrm{R}$ substituents to modulate the spacing between two consecutives molecules within a molecular row (Scheme 2), with the hope therefore to impact the electronic properties of the film while keeping the dipole moment of the molecule unchanged. Fortunately, synthetic methods ${ }^{6}$ allow the preparation and study of a large diversity of new $\mathrm{N}$-substituted quinonoid zwitterions, in particular containing an aryl-substituent.
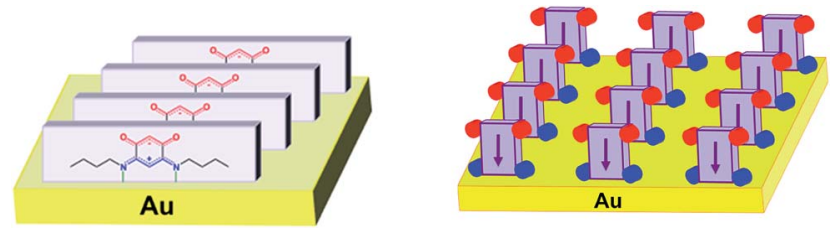

Scheme 2 The molecular arrangement of zwitterions 2 in the first layer of the film formed on a gold surface. The quinonoid zwitterions commonly arrange in molecular rows on a gold substrate (taken from ref. $5 a$, with permission from the PCCP Owner Societies). Parallelepipeds represent the quinonoid core and the arrows indicate the dipole direction. Red and blue spheres represent oxygen and nitrogen atoms, respectively.
To avoid using time-consuming spectroscopies (which are possibly destructive to the more fragile molecular species), we need a screening method to eliminate unpromising molecular candidates. Here we propose to focus on how structural insight provided from single crystal X-ray diffraction studies can be used to select molecular species presenting first neighbors packing geometry of potential interest for conductivity studies. Even though we cannot, a priori, hold that the molecular arrangement observed in the solid state will be retained on thin deposited films, X-ray studies have already been shown to provide useful indicators. ${ }^{5} \mathrm{~A}$ long term goal is to establish for a family of relevant molecules how packing effects in the solid state correlate with the properties of the thin films.

\section{Synthesis}

Several possibilities can be envisaged to chemically modify the steric properties of the R substituent: (1) the length of the linker between the phenyl group and the zwitterionic core, (2) the introduction of a $\mathrm{R}^{\prime}$ substituent (alkyl or aryl) on the alkyl chain, (3) the incorporation of $\mathrm{R}^{\prime}$ substituent on the aromatic part (Scheme 3).

The quinonoid zwitterions presented in Table 1 were isolated in good yields, using synthetic methods previously described in the literature (see the detailed synthetic procedures in the ESI $\dagger)^{5,6}$

\subsection{Crystal structures and packing of the zwitterions}

Single crystals of the new zwitterions 6-9, 12, 13, 15, 19 and 24 were obtained and their molecular structures were elucidated by X-ray diffraction (see details and Fig. S1 to S23 in the ESI $\dagger$ ). In all cases, the six ring carbon atoms, the two $\mathrm{O}$ and two $\mathrm{N}$ atoms are almost coplanar.

Zwitterions 8 and 12 co-crystallize with water or pentane molecules, respectively. Therefore the structural data cannot be exploited for our purpose. Seven other structures determined by X-ray diffraction establish that the molecular arrangement of the zwitterions is highly dependent on the R substituent at the nitrogen atoms (see results and discussion in pages S-33 to S$69 \dagger$ ). Notably, the presence of functional groups such as $\mathrm{NH}_{2}$ or OMe lead to molecular arrangements drastically different from that observed for 5 (Fig. S13 and S14, in ESI $\dagger$ ).

We initially thought that the presence of an additional alkyl or aryl substituent in $\alpha$ position to the nitrogen atom would efficiently modify the intermolecular spacing. We thus expected that the molecular arrangement of zwitterion $\mathbf{1 3}$ would be<smiles>O=C1C=C(Nc2ccccc2)C(=O)C=C1Nc1ccccc1</smiles><smiles></smiles><smiles>O=C1C=C(NCc2ccccc2)C(=O)C=C1NCc1ccccc1</smiles>

Scheme 3 The schematic structures of various quinonoid zwitterions with different pendant groups. 
Table 1 Synthesis of various zwitterions with different $N$-substituents ${ }^{a}$

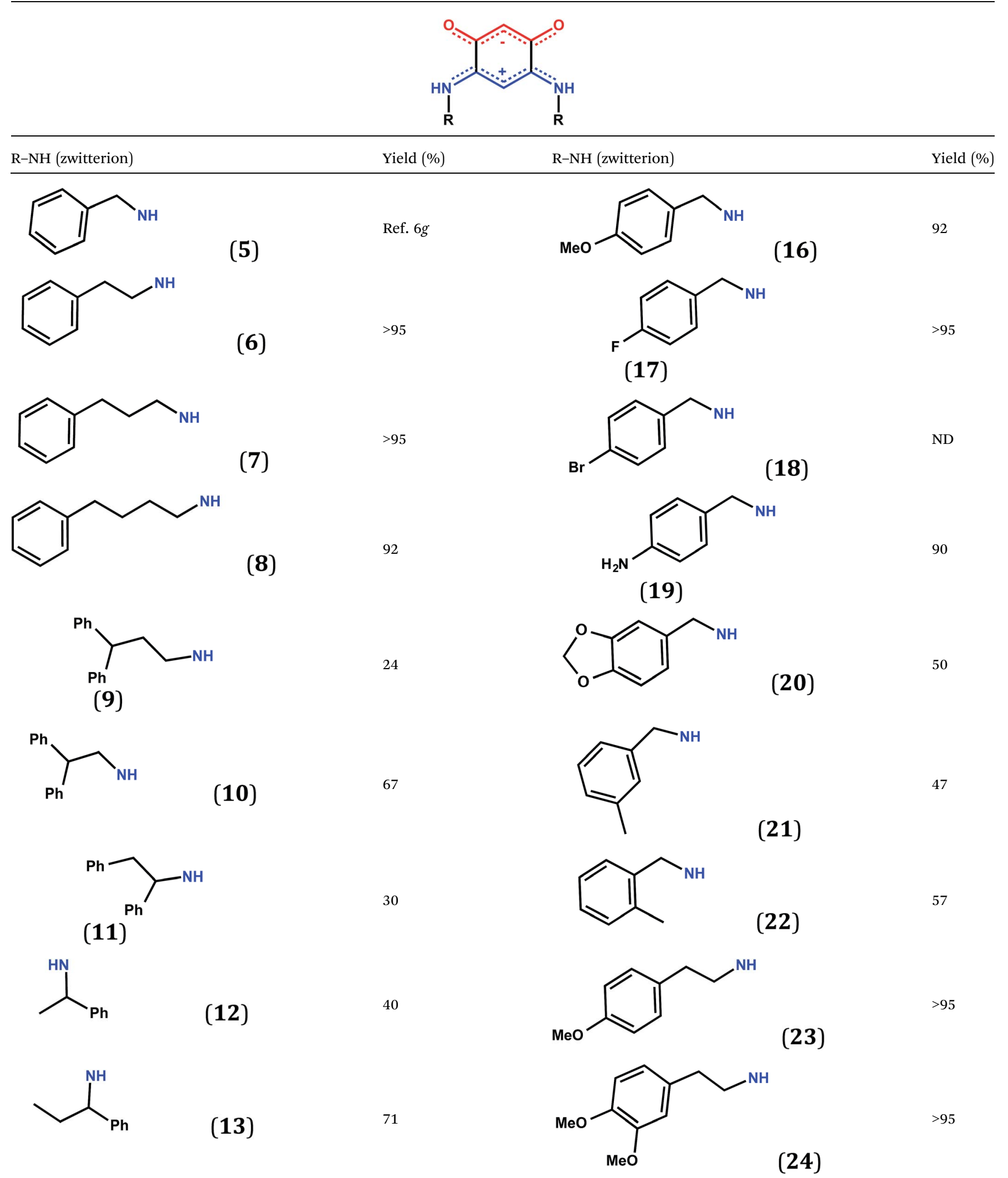


<smiles></smiles>

(15) Yield (\%)

significantly different from that observed for 5. In contrast, we expected only minor differences in packing between 5 and $\mathbf{1 5}$ since a methyl group of $\mathbf{1 5}$ is not bulky and its para-position on the phenyl substituent would further reduce its influence. Furthermore, a methyl substituent is much less likely to create intermolecular interactions than a functional group such as an amine, a hydroxyl, a fluorine or a methoxy group. We thus focused our studies on the three molecules, 5, 13 and 15, used as illustrative examples for comparisons based on simple steric arguments, bulk $\mathrm{X}$-ray diffraction structural insight, and surface studies outcome.

Fig. 1 and 2 show the molecular arrangements deduced from the X-ray diffraction analyses of zwitterions 13 and 15, respectively. Fig. 1a reveals how an infinite row of molecules is formed in a direction orthogonal to the $\mathrm{C}_{6}$ core. Within a row, molecules of $\mathbf{1 3}$ are shifted upward (Fig. 1a) and we observe hydrogen-bonding interactions between a $\mathrm{H}$ atom of each methylene group and the anionic system of the nearest neighbor (Fig. 1b).

Interestingly, zwitterion 13 (Fig. 1a) forms molecular rows resembling those of $\mathbf{5}$ (Fig. 3a). Similar rows are observed on the gold substrate (Scheme 2) and this stacking is crucial for the electronic behavior of the film on the surface. The hydrogen bonding interactions depicted in Fig. 1b are also observed for 5 (Fig. 3b) and they help maintaining the cationic system of one molecule close to the anionic system of a neighboring molecule. We previously attributed the semi-metallic character of the benzyl zwitterion 5 to these interactions. ${ }^{4 d, 5 e}$

In the case of $\mathbf{1 5}$, we also observe the formation of molecular rows in a direction orthogonal to the $\mathrm{C}_{6}$ core (Fig. 2a) but a methylene $\mathrm{H}$ atom interacts with the aryl $\mathrm{C} 1$ carbon while one $\mathrm{H}$ atom from the $p$-Me group interacts with the aryl $\mathrm{C} 4$ carbon of a neighboring molecule (Fig. 2b). The arrangement of the molecules thus differs drastically from that observed in $\mathbf{5}$ (Fig. 3b). Molecules of 15 are shifted 'horizontally' (Fig. 2a)

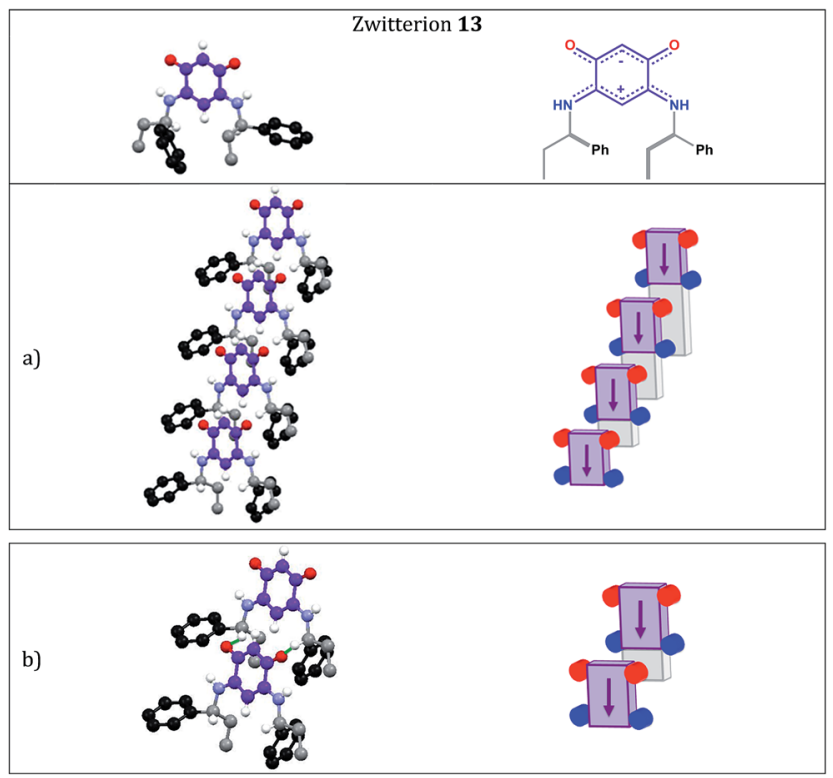

Fig. 1 The molecular arrangement of zwitterions 13 in the crystalline state. (a) A row of molecules. (b) Hydrogen bonding between two neighboring molecules. For clarity, quinonoid cores are indicated in violet and phenyl substituents in black. In the sketch, parallelepipeds represent the quinonoid core and the arrows indicate the dipole direction. Red and blue spheres represent oxygen and nitrogen atoms, respectively. Light grey parallelepipeds are indicated to facilitate the visualization of the molecular arrangement of quinonoid zwitterions. 


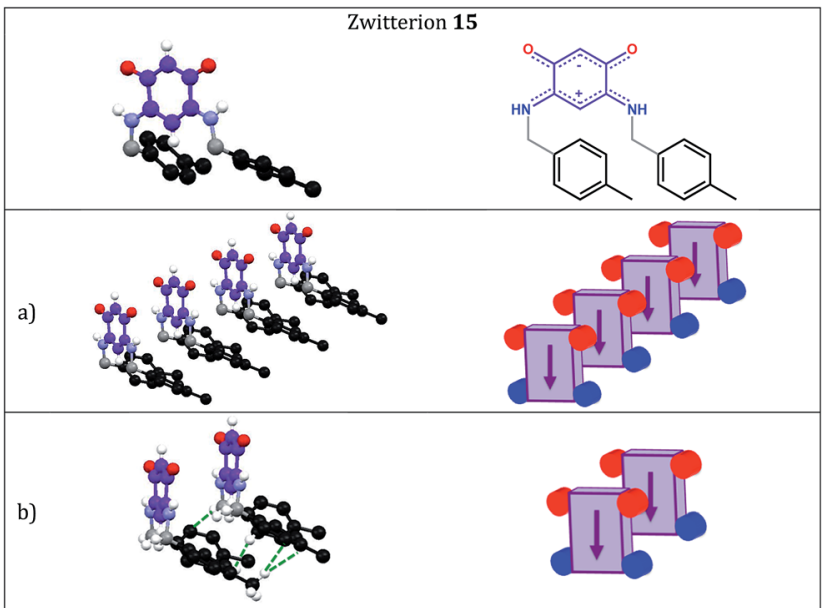

Fig. 2 The molecular arrangement of zwitterions 15 in the crystalline state. (a) A row of molecules. (b) Hydrogen bonding between two neighboring molecules. For clarity, quinonoid cores are indicated in violet and phenyl substituents in black. The parallelepipeds represent the quinonoid core and the arrows indicate the dipole direction. Red and blue spheres represent oxygen and nitrogen atoms, respectively.

whereas molecules of $\mathbf{1 3}$ (Fig. 1a) and $\mathbf{5}$ (Fig. 3a) have a placement characterized by a shift 'upward'.

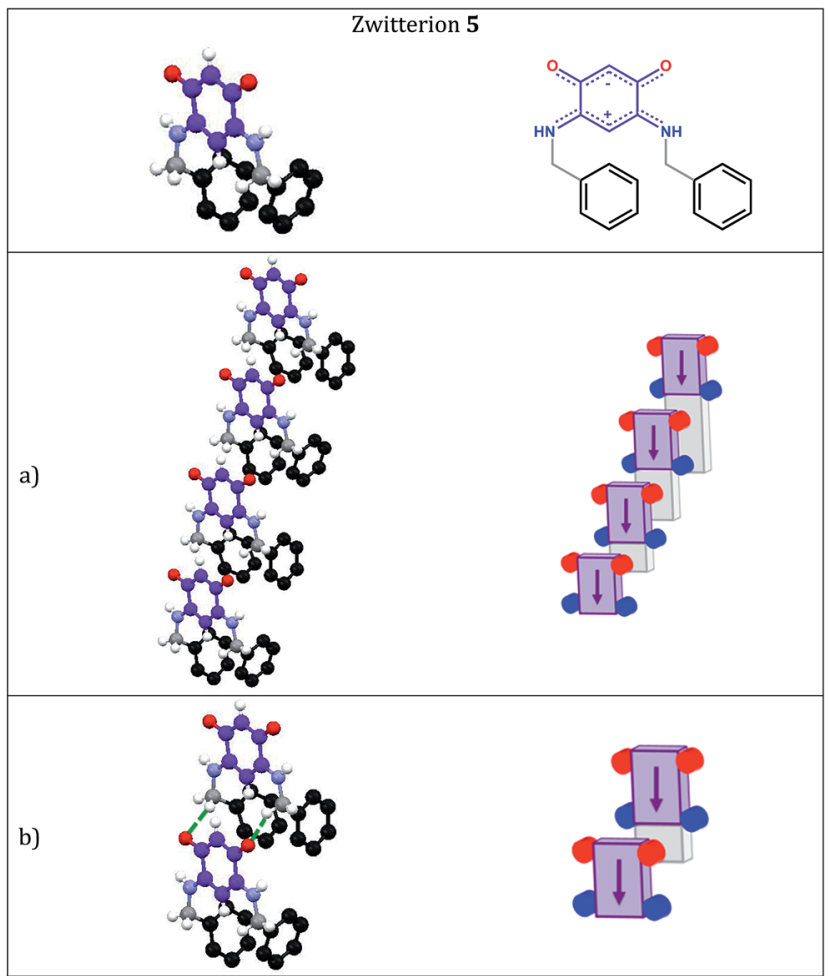

Fig. 3 The molecular arrangement of zwitterions 5 in the crystalline state. (a) A row of molecules. (b) Hydrogen bonding between two neighboring molecules. The parallelepipeds represent the quinonoid core and the arrows indicate the dipole direction. Red and blue spheres represent oxygen and nitrogen atoms, respectively. Light grey parallelepipeds are indicated to facilitate the visualization of the molecular arrangement of quinonoid zwitterions.

Within a molecular row, zwitterions $\mathbf{1 3}$ form a similar arrangement to 5, whereas significant differences are observed with 15. To evaluate the impact of structural modifications on the intermolecular spacing, three indicators can be identified: (1) the spacing $D^{\mathrm{PL}}$ between the mean planes passing through the $\mathrm{C}_{6} \mathrm{O}_{2} \mathrm{~N}_{2}$ quinonoid cores; (2) the interatomic oxygen-oxygen $\left(D^{\mathrm{O}-\mathrm{O}}\right)$ and nitrogen-nitrogen $\left(D^{\mathrm{N}-\mathrm{N}}\right)$ distances between two consecutive molecules in a row (these values are identical when the molecules are strictly parallel to each other) and (3) the distances $\left(D^{\mathrm{O}-\mathrm{N}}\right)$ between the nearest oxygen and nitrogen atoms of two consecutive molecules in a row (only one value is given when the molecules are strictly parallel to each other). These values in $\mathbf{1 3}$ and $\mathbf{1 5}$ are compared to those found in $\mathbf{5}$ (Table 2).

The intermolecular spacings observed for $\mathbf{1 3}$ (Table 2 and Fig. 4) are very close to those found for the benzyl zwitterion 5 (Table 2 and Fig. 6). The comparisons between zwitterions 5 and 13 reveal that an increased steric hindrance of the $\mathrm{R}$ substituent does not automatically result in an increased intermolecular spacing.

The $D^{\mathrm{O}-\mathrm{O}}$ (or $D^{\mathrm{N}-\mathrm{N}}$ ) distance in 15 (Table 2 and Fig. 5) is considerably smaller than in $\mathbf{5}$, whereas the $D^{\mathrm{O}-\mathrm{N}}$ distance in $\mathbf{1 5}$ is significantly larger than in $\mathbf{5}$. We also note that the $D^{\mathrm{O}-\mathrm{N}}$ distance of $5.2 \AA$ in zwitterions 3 and 4 is significantly larger than in $15 .^{5 e}$ Therefore, we can be relatively confident about the potential electronic transport properties of a molecular film of zwitterion 15 on a gold surface. Since the spacing $D^{\mathrm{PL}}$ in 15 is larger than in $\mathbf{5}$ and molecules are horizontally shifted, we can hypothesize that interactions between the anionic and cationic $\pi$-systems would be less favored than in 5 . The arrangement found in $\mathbf{1 5}$ is more similar to that of $\mathbf{3}$ than of $\mathbf{5}$.

Table 2 Spacings $(\AA \AA)$ measured within molecular row of zwitterions 5 , 13 and 15

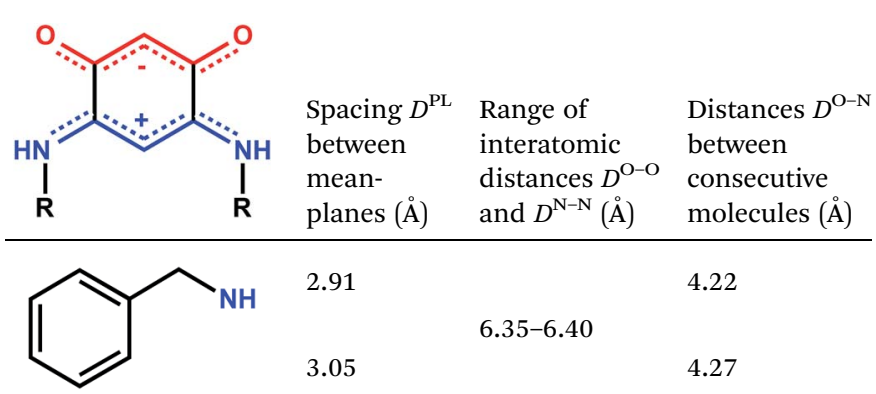

(5)<smiles>CCC(N)c1ccccc1</smiles>

3.01

6.05

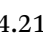

4.4

3.46

4.80

(15) 


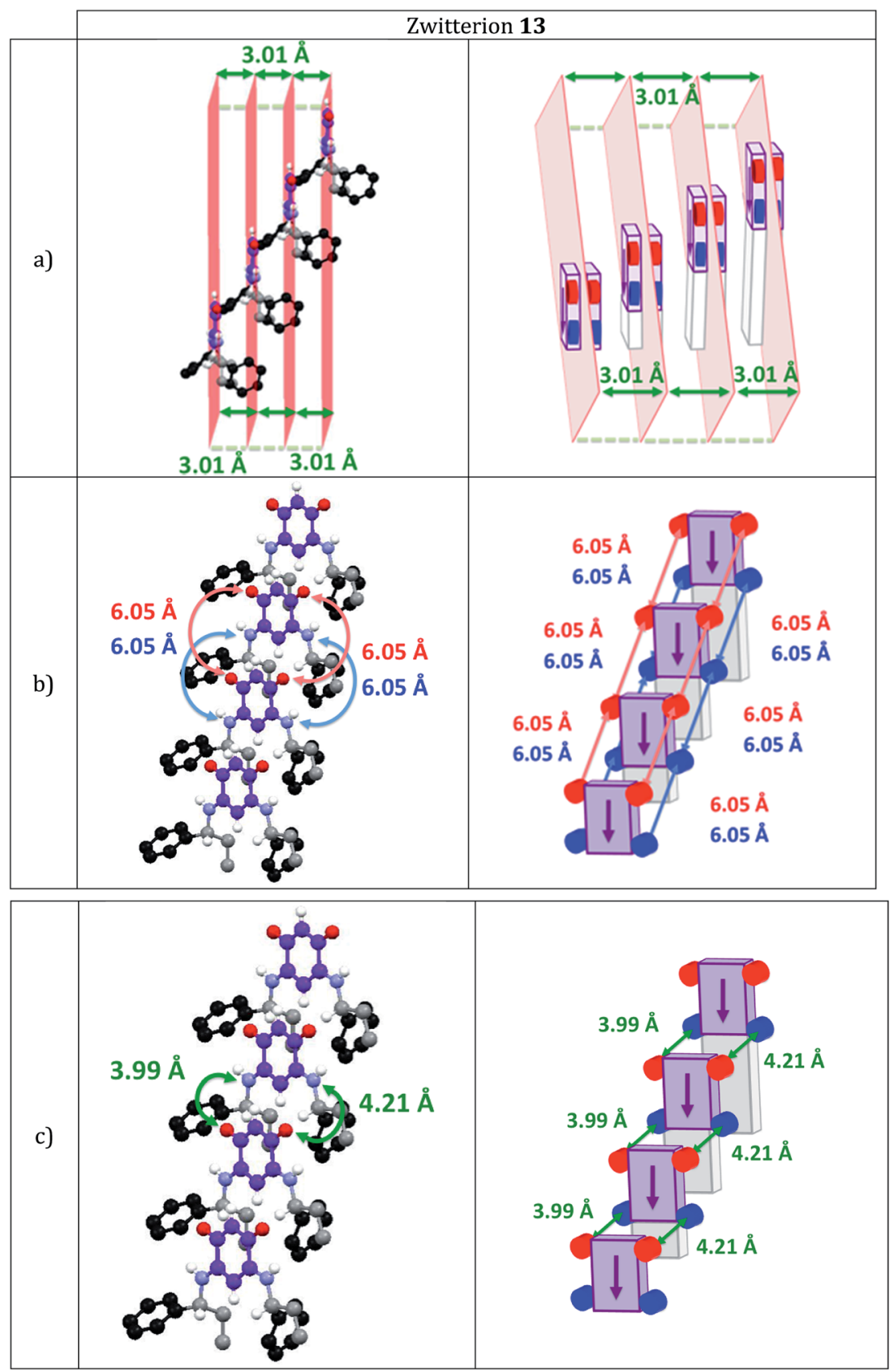

Fig. 4 The characteristic intermolecular spacings in a molecular row of 13. (a) The spacing $D^{\mathrm{PL}}$ between mean-planes. (b) Interatomic distances $D^{\mathrm{O}-\mathrm{O}}$ and $D^{\mathrm{N}-\mathrm{N}}$ between two consecutive molecules. (c) Distances $D^{\mathrm{O}-\mathrm{N}}$ between two consecutive molecules. For clarity, the quinonoid cores are indicated in violet and phenyl substituents in black. The parallelepipeds represent the quinonoid core and the arrows indicate the dipole direction. Red and blue spheres represent oxygen and nitrogen atoms, respectively. Light pink parallelepipeds represent mid-planes of the quinonoid cores. Light grey parallelepipeds are indicated to facilitate the visualization of the molecular arrangement of the quinonoid zwitterions.

Based on the chemical similarities between zwitterions 15 and 5 and the differences between 13 and $\mathbf{5}$, we anticipated the properties of the films made from 15 to be more similar to those of 5 than to those of 13. However, the structural analysis of the intermolecular spacings revealed the opposite. The difference between the expected and the obtained structural results was so intriguing that the functionalization of the gold surface by zwitterion 13 and $\mathbf{1 5}$ was an obvious next step. A gold surface functionalized with zwitterion 15 should allow us to assess whether the electronic properties exhibited by a molecular film of zwitterion 15 in anyway resemble those of a zwitterion 5 molecular film. ${ }^{4 d, 5 e}$ At issue is whether a film of zwitterion $\mathbf{1 5}$ on a gold surface would also have a semi-metallic character, like that observed for molecular films of zwitterion $\mathbf{5 .}^{\mathbf{4}, 5 e}$ Although the intermolecular spacings observed for $\mathbf{5}$ and $\mathbf{1 3}$ are very similar, zwitterion $\mathbf{1 5}$ is chemically more similar to 5 than $\mathbf{1 3}$. Furthermore, zwitterion 13 may provide an opportunity to cover a gold surface with a molecular film of enantiopure molecules possessing a strong dipole. 


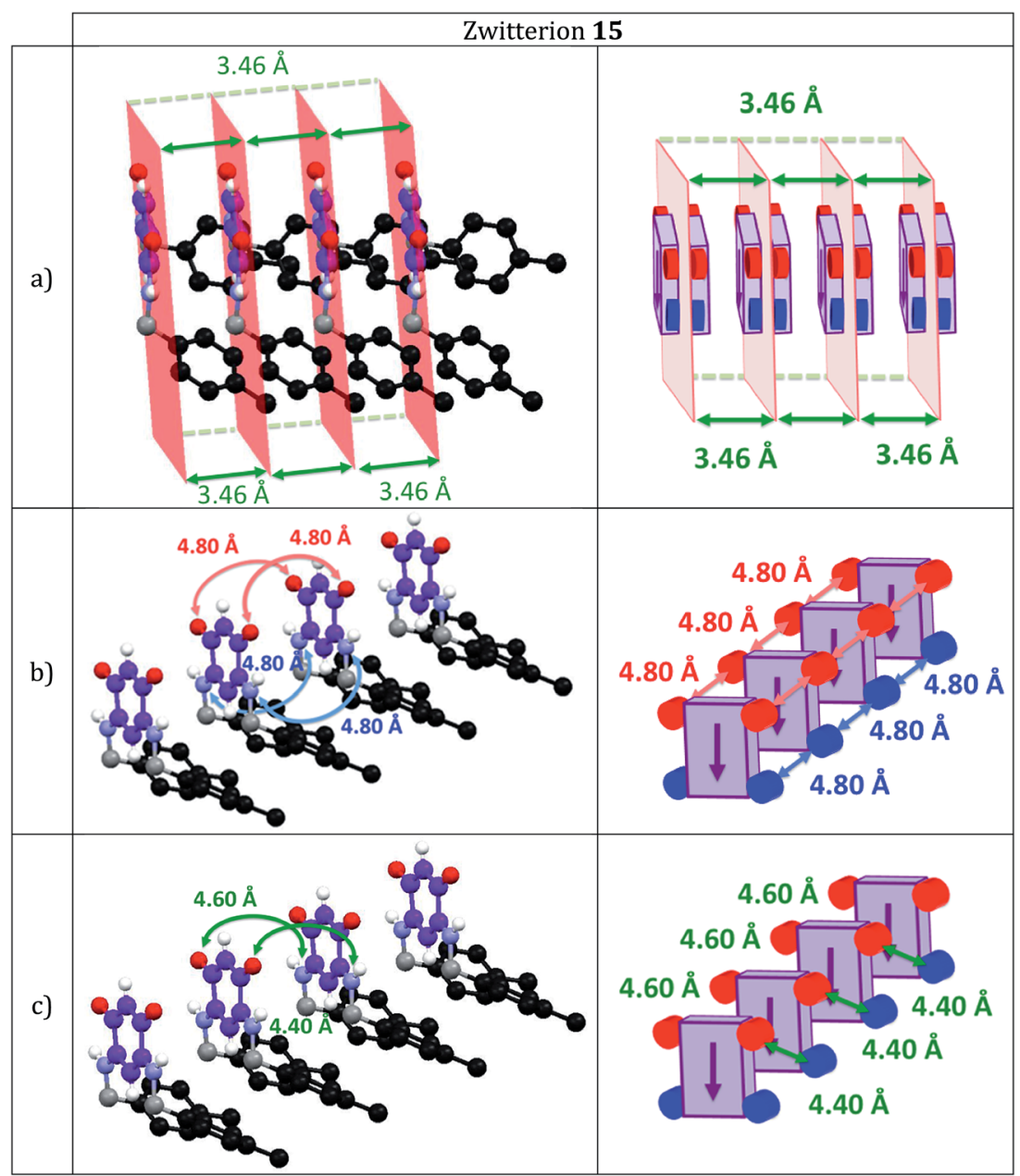

Fig. 5 The characteristic intermolecular spacings in a molecular row of 15. (a) The spacing $D^{\mathrm{PL}}$ between mean-planes. (b) Interatomic distances $D^{\mathrm{O}-\mathrm{O}}$ and $D^{\mathrm{N}-\mathrm{N}}$ between two consecutive molecules. (c) Distances $D^{\mathrm{O}-\mathrm{N}}$ between two consecutive molecules. For clarity, the quinonoid cores are indicated in violet and phenyl substituents in black. The parallelepipeds represent the quinonoid core and the arrows indicate the dipole direction. Red and blue spheres represent oxygen and nitrogen atoms, respectively. Light pink parallelepipeds represent mid-planes of the quinonoid cores.

However, the steric hindrance in $\alpha$ position to nitrogen could affect the anchoring of the molecule on the surface. Zwitterion 13 was found by IR spectroscopies not to adhere well to gold, unlike zwitterions $\mathbf{5}$ and $\mathbf{1 5}$ (as discussed below). Indeed, we recently emphasized how the presence of a methylene group in $\alpha$ position to the nitrogen atom is crucial for the anchoring of quinonoid zwitterions on a gold surface through $\mathrm{N}-\mathrm{Au}$ interaction. ${ }^{5 j}$ However, we have also shown that quinonoid molecular films on a gold surface can be obtained using an $\mathrm{N}$-aryl substituent as anchor.

\subsection{Thin films on gold}

Gold surfaces were functionalized using the previously published methodology which allows the formation of a thin molecular film in the $\mathrm{nm}$ thickness range. ${ }^{5 \boldsymbol{a}, \boldsymbol{b}, \boldsymbol{e}}$ IR spectroscopy is commonly used to characterize molecular adsorption on a metal substrate, ${ }^{7}$ and to establish molecular integrity in the submonolayer limit. ${ }^{7 d}$ The characteristic IR spectroscopic fingerprint of $\mathbf{1 5}$ (Fig. 6) is consistent with previous results on zwitterion molecular films, ${ }^{5 a, e}$ and the calculated vibrational modes of the parent quinonoid zwitterions, ${ }^{8} \mathrm{C}_{6} \mathrm{H}_{2}(\cdots \mathrm{O})_{2}\left(\cdots \mathrm{NH}_{2}\right)_{2}$, especially the $1102 \mathrm{~cm}^{-1} \mathrm{~b}_{2}$ mode (dashed line in Fig. 7). Yet the IR spectra of a gold surface exposed to $\mathbf{1 3}$ does not show the fingerprints of the zwitterion, indicating that little or no molecules of $\mathbf{1 3}$ were anchored on the surface (Fig. S91, ESI $\dagger$ ). In this regard, zwitterion 15 is similar to zwitterion 5, as both anchor well to gold.

There is also strong evidence from spatial IR microscopy for preferred localization of the zwitterion 15 on gold, rather than the silicon oxide substrate. The IR spectromicroscopy confirmed the formation of a molecular film of $\mathbf{1 5}$ on the gold surface and provided an anchoring map of this zwitterion on a patterned substrate $\left(\mathrm{Au} / \mathrm{SiO}_{2}\right)$ showing a selective anchoring of 15 on gold. This is one of the best examples of preferential anchoring of a zwitterion, ${ }^{5 \boldsymbol{a}, \boldsymbol{e}}$ and the sole example of spatial localization for a quinonoid zwitterion thin film.

The combined photoemission and inverse photoemission spectra, Fig. 8, are also consistent with an "intact" zwitterion 15 forming a self-assembled monolayer/bilayer thin film on gold. These spectra resemble those taken for other similar zwitterions on gold, ${ }^{5}$ which is not surprising as the molecular orbitals near the chemical potential are dominated by the oxocyclohexa-1,4- 


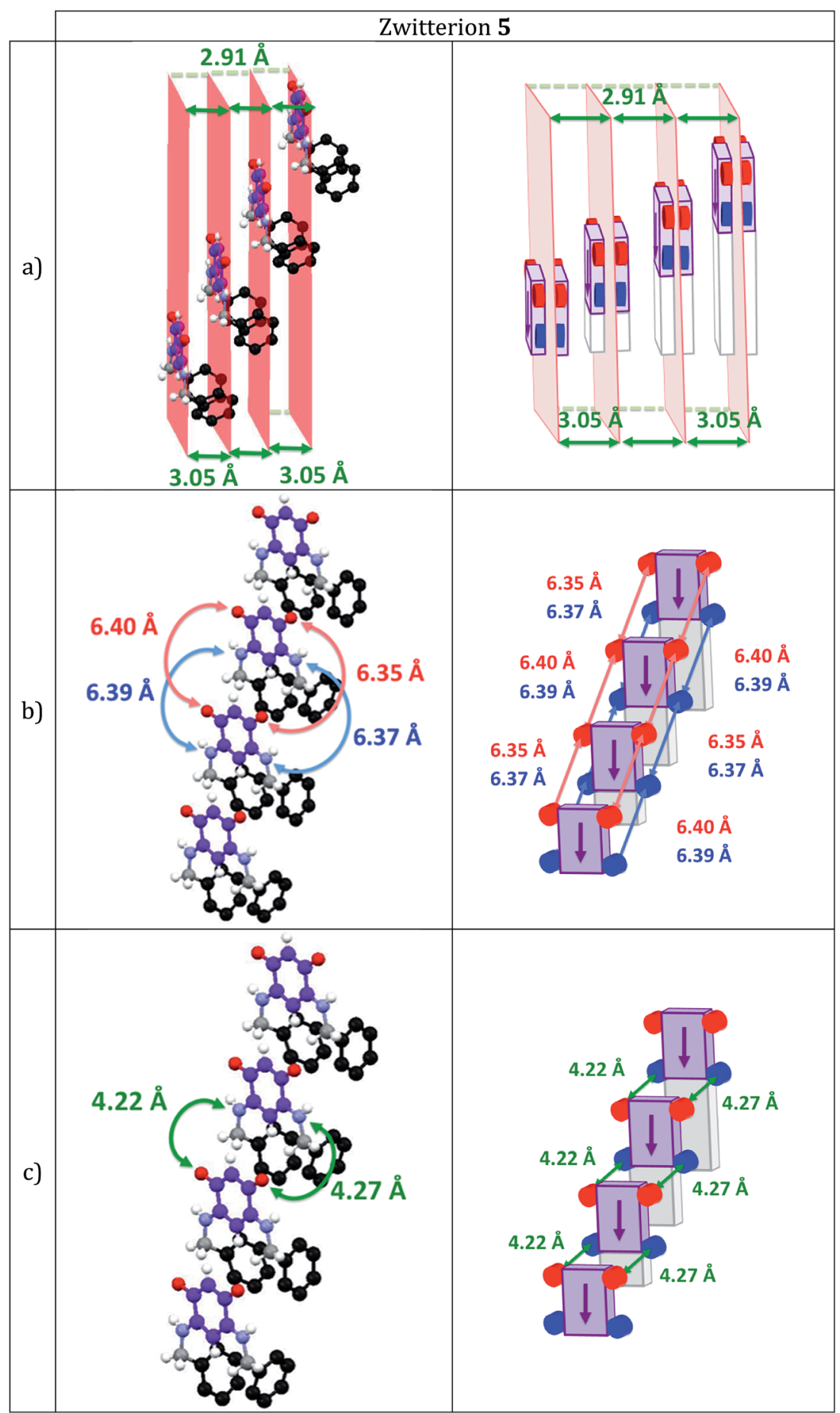

Fig. 6 The characteristic intermolecular spacings in a molecular row of 5. (a) The spacing $D^{\mathrm{PL}}$ between mean-planes. (b) Interatomic distances $D^{\mathrm{O}-\mathrm{O}}$ and $D^{\mathrm{N}-\mathrm{N}}$ between two consecutive molecules. (c) Distances $D^{\mathrm{O}-\mathrm{N}}$ between two consecutive molecules. For clarity, the quinonoid cores are indicated in violet and phenyl substituents in black. The parallelepipeds represent the quinonoid core and the arrows indicate the dipole direction. Red and blue spheres represent oxygen and nitrogen atoms, respectively. Light pink parallelepipeds represent the mid-planes of quinonoid cores. Light grey parallelepipeds are indicated to facilitate the visualization of the molecular arrangement of quinonoid zwitterions.

dien-1-olate backbone. Unusual for most organic SAM layers is that the chemical potential $\left(E-E_{\mathrm{F}}=0\right)$ falls very close to the lowest unoccupied molecular orbital. While we have not measured directly the majority carrier in these organic films, such a placement of the chemical potential strongly suggests that these films of $\mathbf{1 5}$ are n-type, as was observed for the zwitterion $5 .^{5 e}$

Inverse photoemission is highly surface sensitive: if the oxocyclohexa-1,4-dien-1-olate backbone was oriented towards the molecular film vacuum interface, the inverse photoemission 


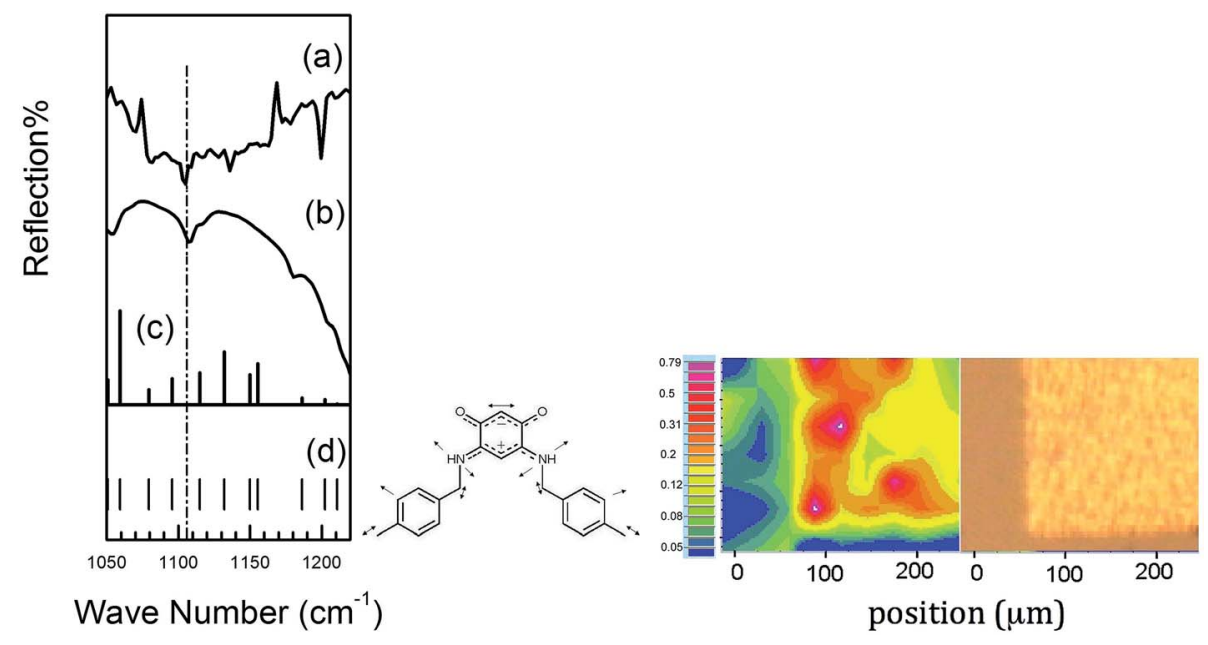

Fig. 7 The IR spectrum of the zwitterion 15 (a) compared to the synchrotron radiation-based FTIR spectrum of the thin film SAM modified gold substrate (b) and the calculated vibrational spectrum (c) that includes the relative oscillator strengths applied to the vibrational eigen values (d). The key modes are schematically indicated. The synchrotron radiation-based FTIR spatial spectra-microscopy, based on the - $\mathrm{NH}-$ wagging mode of the zwitterion 15 clearly shows the spatial localization on the gold, rather than silicon oxide substrate.

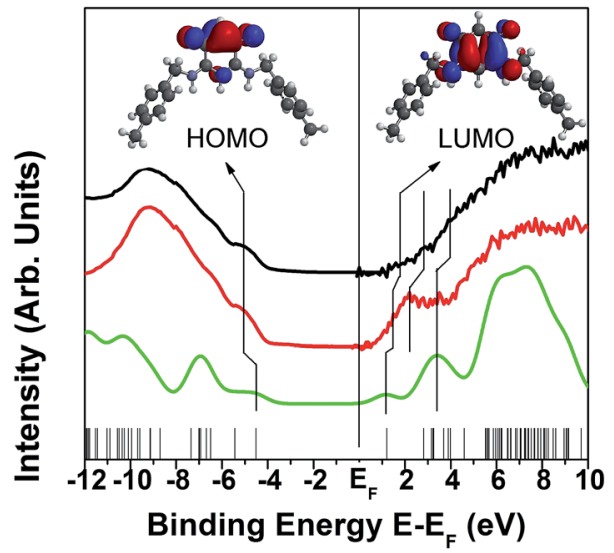

Fig. 8 The combined photoemission (left) and inverse photoemission (right) of the zwitterion 15, at low (red) and higher coverage (black) on gold. These data are compared to occupied and unoccupied DFT density state calculations of the zwitterion 15 (green), using a $1 \mathrm{eV}$ Gaussian broadening of the eigenvalues. The actual calculated eigenvalues are plotted at the bottom, with the individual highest and lowest molecular orbitals indicated and distinguished by schematics of the orbital schemes for the HOMO and LUMO.

LUMO and LUMO+1 features should appear, as observed for the thinnest films, as seen in Fig. 8 (red on the right-hand side). The decrease in the inverse photoemission spectroscopy peaks amplitudes of the LUMO and LUMO+1 with increasing film thickness, as seen in Fig. 8 (red to black on the righthand side), is indicative of increasing disorder in the thicker films. As there is no such significant change in the photoemission spectra (the left side of Fig. 8), which is less surface sensitive, the changes observed in the inverse photoemission are unlikely to be due to molecular degradation, polymerization or other unwanted feature as might occur under an electron or photon fluence. This is consistent with the results reported elsewhere ${ }^{5}$ that many zwitterions of this family are quite robust in ultra high vacuum under photoemission and inverse photoemission conditions. There is a key difference between films prepared from zwitterions 5 and 15: those of 5 behave very close to a semimetal, ${ }^{5 e}$ while those of 15 exhibit a very low density of carriers at the Fermi level, their chemical potential falling well within the HOMO-LUMO gap (although close(r) to the LUMO), and can be considered as mostly insulators (with n-type defects). This significant difference is very surprising given the sole difference between the two molecules being a remote methyl group.

\section{Conclusion and perspectives}

In an effort to identify potential candidate quinonoid zwitterions that could give rise to molecular films exhibiting electronic properties close to semi-metallic as found with $\mathbf{5}$, we found that among all the zwitterions structurally analyzed by X-ray diffraction, 13 shows a molecular arrangement similar to that of the benzyl compound $\mathbf{5}$ and is therefore the best candidate. However, it cannot be stabilized in thin films over gold. The molecule 15 has the nearest chemical composition to 5, but detailed comparisons indicate that molecular arrangements are highly dependent on the $\mathrm{R}$ substituent on nitrogen. We also highlight the difficulty to predict to what extent the molecular arrangement in the solid state will be affected by even relatively minor structural modifications. A striking feature is that the presence of a methyl group in para-position on the aryl substituent can change drastically the electronic structure of the quinonoid zwitterion molecular film on the gold surface. This can be correlated with the observation that the presence of this methyl group leads to major modifications of the molecular packing in the solid state. This is also consistent with our previous results showing that the zwitterion 16 is anchored more strongly on the graphene surface when compared to the benzyl zwitterion 5, again emphasizing the role of functional 
groups on the aromatic substituent. ${ }^{5 h}$ In a wider context, this study allowed us to expand our library of quinonoid compounds to functionalized, enantiopure, or sterically-hindered molecules in order to identify candidates with a suitable $\mathrm{R}$ substituent for interesting electronic properties of their films on gold.

\section{Experimental section}

\subsection{Synthesis}

General. Commercial 4,6-diaminoresorcinol dihydrochloride and functional amines were used directly without further purification. Solvents were freshly distilled under argon prior to use. Reactions under microwave irradiations were performed in a closed system (10 $\mathrm{ml}$ CEM reactor) and using a microwave CEM discover SP2011. ${ }^{1} \mathrm{H}$ NMR spectra were recorded in $\mathrm{CDCl}_{3}$ on a Bruker $500 \mathrm{MHz}$ instrument, operating at $125 \mathrm{MHz}$ for ${ }^{13} \mathrm{C}$ spectra and $500 \mathrm{MHz}$ for ${ }^{1} \mathrm{H}$ spectra. Chemical shifts are given in $\delta$ units, in parts per million (ppm) relative to the singlet at $\delta=7.26$ for $\mathrm{CHCl}_{3}$. The splittings were designated as s, singlet; d, doublet; t, triplet; $\mathrm{m}$, multiplet; br, broad.

The synthetic procedures and characterization of the new zwitterionic molecules are given in the ESI (p S-10 to S-27†) and the NMR spectra are included in pages S-71 to S-243. $\dagger$

\subsection{Crystal structure determinations}

X-ray diffraction data were collected on a Kappa CCD diffractometer using graphite-monochromated Mo-K $\alpha$ radiation $(\lambda=$ $0.71073 \AA$ Å) (Table S1†). Data were collected using $\psi$ scans, the structures were solved by direct methods using the SHELX97 software, ${ }^{9}$ and the refinement was by full-matrix least squares on $F^{2}$. No absorption or self-absorption correction was used. All non-hydrogen atoms were refined anisotropically, with $\mathrm{H}$ atoms introduced as fixed contributors $\left(d(\mathrm{C}-\mathrm{H})=0.95 \AA, U_{11}=0.04\right)$. Crystallographic data (excluding structure factors) have been deposited in the Cambridge Crystallographic Data Centre as Supplementary Publication: CCDC. 1531545-1531553.†

\subsection{Functionalization of the gold surfaces}

The zwitterionic molecules were deposited on clean gold substrates from a $\mathrm{CH}_{2} \mathrm{Cl}_{2}$ solution. Typical overnight exposure to a $0.8 \mathrm{mmol}$ solution $\left(0.2 \mathrm{~g} \mathrm{l}^{-1}\right)$ was followed by extensive ethanol washing to remove the excess molecules not bonded to the Au substrate. First, to remove drops of solution on the surface, the functionalized surface was dipped into ethanol. Then the surface was immersed during one minute in $3 \mathrm{ml}$ of absolute ethanol. The latter operation was repeated two more times, and fresh ethanol was used each time. The samples were dried and kept under nitrogen atmosphere.

\subsection{Spectroscopy}

Combined photoemission and inverse photoemission spectra were taken of the films, for molecular coverages ranging from nominally sub-monolayer to the thicker multilayer films. The ultraviolet photoemission (UPS) and inverse photoemission (IPES) spectra were taken in a single ultrahigh vacuum chamber to study the placement of both occupied and unoccupied molecular orbitals of the adsorbates as a function of adsorbate film coverage (thickness). The IPES were obtained by using variable incident energy electrons while measuring the emitted photons at a fixed energy $(9.7 \mathrm{eV})$ using a Geiger-Müller detector. $^{10-12}$ The instrumental line width was $\sim 400 \mathrm{meV}$, as described elsewhere..$^{a, 5 b, 5,5,5,10,11,12,13}$ The angle integrated photoemission (UPS) studies were carried out using a helium lamp at $h v=21.2 \mathrm{eV}$ (He I) and a Phi hemispherical electron analyzer with an angular acceptance of $\pm 10^{\circ}$ or more, as described in detail elsewhere. ${ }^{5 a, 5 b, 5,5 e, 10,12,14}$ In both photoemission and inverse photoemission measurements, the binding energies are referenced with respect to the Fermi edge of gold in intimate contact with the sample surface and the photoemitted (UPS, XPS) or incident (IPES) electrons were collected or incident along the sample surface normal.

The infrared (IR) micro-spectroscopy measurements for the $p$-benzoquinonemonoimine zwitterions adsorbed on gold were performed at the Center for Advanced Microstructures and Devices (CAMD) synchrotron facility by means of the IR reflection mode of Thermo Nicolet continuum microscope. ${ }^{5 a}$ The spectrum of the zwitterion of Fig. 7a, was recorded on a Nicolet 6700 FT-IR spectrometer (in the ATR mode, diamond crystal).

\subsection{Theoretical methodologies}

To model the zwitterion vibrational modes theoretical calculations were performed using the SPARTAN density functional theory (DFT) ab initio package. Calculations were undertaken with a standard 3-21G basis set and the hybrid B3LYP functional, seen to be appropriate for large donor-acceptor molecular systems. ${ }^{15}$ The initial geometry was obtained by assigning the molecule standard bond lengths and then optimizing at the self-consistent field (SCF) level and further refined at the SCF-3$21 \mathrm{G}$ level. The solutions from the improved force field calculations provided the vibrational frequencies of zwitterions summarized in Fig. 7. Other theoretical approaches generally were seen to provide very similar outcome. The main limitation of the calculations is that none of the models or methodologies included anharmonic corrections to the vibrational modes, but such an effort is beyond the scope of this paper.

Using the same density functional theory approach, but with the more extended basis set of $31 \mathrm{G}^{*}$, the ground state molecular orbital eigenvalues were obtained, as plotted in Fig. 8, and checked again using more limited modified neglect of differential overlap parametric method (NDO-PM3) calculations, as well as DFT with and without the generalized gradient approximation (GGA). Geometry optimization of the $p$-benzoquinonemonoimine zwitterion systems was performed by obtaining the lowest restricted Hartree-Fock energy states. Calculations of the density of states (Fig. 8), are based on the more simplistic single molecule semiempirical method NDO-PM3 (neglect of differential diatomic overlap, parametric model number 3) model calculations, within the Hartree-Fock formalism, consistent with other efforts showing good agreement with the photoemission and inverse photoemission spectra for zwitterions like the above discussed zwitterions. ${ }^{5 f}$ Although PM3 is a simplistic 
semiempirical ground state calculation, we preferred it over density functional theory (DFT), notorious for under estimating the band gap in some cases by a factor 2 or more,${ }^{16}$ particularly for molecular systems, a problem found with our own B3LYP density functional theory calculations and those of others ${ }^{17,18}$ (i.e. about $3.6 \mathrm{eV}$ ) using the extended $6-31 \mathrm{G}^{*}$ basis set. The calculated density of states (DOS) were obtained by applying equal Gaussian envelopes of $1 \mathrm{eV}$ full width half maximum to each molecular orbital to account for the solid state broadening in photoemission and inverse photoemission and then summing. To account for the effect of work function on the orbital energies, and other solid state effects, the model density of states calculation was rigidly shifted in energy. No corrections were made for molecular interactions and final state effects. This is typical of the density functional theory applied to quinonoid zwitterions, even when using the extended $6-31 \mathrm{G}^{*}$ basis set, ${ }^{5 d, 5,5,5,8,17,18,19,20}$ but there are some solid state calculations that have been compared with experiment. ${ }^{4 d}$

\section{Acknowledgements}

This research was supported by the Centre National de la Recherche Scientifique and the Ministère de la Recherche et des Nouvelles Technologies (Paris), the ANR (07-BLAN-0274-04), the National Science Foundation through the Division of Chemistry and Division of Materials Research (NSF-1565692). Partial financial support of the Nebraska Center for Energy Sciences Research (cycle 11) is also gratefully acknowledged, as well as the technical help form the STnano cleanroom facilty in Strasbourg. Some measurements were performed at the Center for Advanced Microstructure and Devices, which is supported by the Louisiana Board of Regents.

\section{References}

1 (a) Y. Yuan, T. J. Reece, P. Sharma, S. Poddar, S. Ducharme, A. Gruverman, Y. Yang and J. Huang, Nat. Mater., 2011, 10, 296-302; (b) Y. Yuan, P. Sharma, Z. Xiao, S. Poddar, A. Gruverman, S. Ducharme and J. Huang, Energy Environ. Sci., 2012, 5, 8558-8563; (c) B. Yang, Y. Yuan, P. Sharma, S. Poddar, R. Korlacki, S. Ducharme, A. Gruverman, R. Saraf and J. Huang, Adv. Mater., 2012, 24, 1455-1460; (d) K. Sun, B. M. Zhao, V. Murugesan, A. Kumar, K. Y. Zeng, J. Subbiah, W. W. H. Wong, D. J. Jones and J. Y. Ouyang, J. Mater. Chem., 2012, 22, 24155-24165.

2 Selected reviews: (a) R. M. Metzger, J. Mater. Chem., 2008, 18, 4364-4396; (b) G. Jiang, Y. Song, X. Guo, D. Zhang and D. Zhu, Adv. Mater., 2008, 20, 2888-2898; (c) L. Miozzo, A. Yassar and G. Horowitz, J. Mater. Chem., 2010, 20, 25132538; (d) H. Dong, C. Wang and W. Hu, Chem. Commun., 2010, 46, 5211-5222; (e) S. Karthaeuser, J. Phys.: Condens. Matter, 2011, 23, 013001; $(f)$ F. G. Brunetti, J. L. López, C. Atienza and N. Martín, J. Mater. Chem., 2012, 22, 41884205.

3 Selected reviews: (a) D. Canevet, M. Salle, G. Zhang, D. Zhang and D. Zhu, Chem. Commun., 2009, 2245-2269; (b) T. Iimori and N. Ohta, J. Phys. Chem. C, 2014, 118, 7251-7260.
4 (a) S. Nakatsuji, M. Nobusawa, H. Suzuki, H. Akutsu and J.-I. Yamada, J. Org. Chem., 2009, 74, 9345-9350; (b) A. ElGhayoury, C. Mézière, S. Simonov, L. Zorina, M. Cobián, E. Canadell, C. Rovira, B. Náfrádi, B. Sipos, L. Forró and P. Batail, Chem.-Eur. J., 2010, 16, 14051-14059; (c) H. Suzuki, H. Akutsu, J.-I. Yamada and S. Nakatsuji, Crystals, 2012, 2, 662-668; (d) L. G. Rosa, J. Velev, Z. Zhang, J. Alvira, O. Vega, G. Diaz, L. Routaboul, P. Braunstein, B. Doudin, Y. B. Losovyj and P. A. Dowben, Phys. Status Solidi B, 2012, 249, 1571-1576; (e) T. Isono, H. Kamo, A. Ueda, K. Takahashi, A. Nakao, R. Kumai, H. Nakao, K. Kobayashi, Y. Murakami and H. Mori, Nat. Commun., 2013, 4, 2352-2358; (f) J. W. L. Wong, A. Mailman, K. Lekin, S. M. Winter, W. Yong, J. Zhao, S. V. Garimella, J. S. Tse, R. A. Secco, S. Desgreniers, Y. Ohishi, F. Borondics and R. T. Oakley, J. Am. Chem. Soc., 2014, 136, 1070-1081; (g) S. E. Brown, Phys. C, 2015, 514, 279-289; $(h)$ D. Jerome and S. Yonezawa, C. R. Phys., 2016, 17, 357-375; (i) A. Mailman, A. A. Leitch, W. Yong, E. Steven, S. M. Winter, R. C. M. Claridge, A. Assoud, J. S. Tse, S. Desgreniers, R. A. Secco and R. T. Oakley, J. Am. Chem. Soc., 2017, 139, 2180-2183.

5 (a) J. Xiao, Z. Zhang, D. Wu, L. Routaboul, P. Braunstein, B. Doudin, Y. B. Losovyj, O. Kizilkaya, L. G. Rosa, C. N. Borca, A. Gruverman and P. A. Dowben, Phys. Chem. Chem. Phys., 2010, 12, 10329-10340; (b) Z. Zhang, J. Alvira, X. Barbosa, L. G. Rosa, L. Routaboul, P. Braunstein, B. Doudin and P. A. Dowben, J. Phys. Chem. C, 2011, 115, 2812-2818; (c) L. Kong, G. J. Perez Medina, J. A. Colon Santana, F. Wong, M. Bonilla, D. A. Colon Amill, L. G. Rosa, L. Routaboul, P. Braunstein, B. Doudin, C.-M. Lee, J. Choi, J. Xiao and P. A. Dowben, Carbon, 2012, 50, 1981-1986; (d) D. A. Kunkel, S. Simpson, J. Nitz, G. A. Rojas, E. Zurek, L. Routaboul, B. Doudin, P. Braunstein, P. A. Dowben and A. Enders, Chem. Commun., 2012, 48, 7143-7145; (e) L. Routaboul, P. Braunstein, J. Xiao, Z. Zhang, P. A. Dowben, G. Dalmas, V. Da Costa, O. Felix, G. Decher, L. G. Rosa and B. Doudin, J. Am. Chem. Soc., 2012, 134, 8494-8506; (f) Y. Fang, P. Nguyen, O. Ivasenko, M. P. Aviles, E. Kebede, M. S. Askari, X. Ottenwaelder, U. Ziener, O. Siri and L. A. Cuccia, Chem. Commun., 2011, 47, 11255-11257; $(g)$ P. A. Dowben, D. A. Kunkel, A. Enders, L. G. Rosa, L. Routaboul, B. Doudin and P. Braunstein, Top. Catal., 2013, 56, 1096-1103; (h) L. Kong, L. Routaboul, P. Braunstein, H.-G. Park, J. Choi, J. P. C. Cordova, E. Vega, L. G. Rosa, B. Doudin and P. A. Dowben, RSC Adv., 2013, 3, 10956-10961; (i) S. Simpson, D. A. Kunkel, J. Hooper, J. Nitz, P. A. Dowben, L. Routaboul, P. Braunstein, B. Doudin, A. Enders and E. Zurek, J. Phys. Chem. C, 2013, 117, 16406-16415; (j) M. Yuan, I. Tanabe, J.-M. BernardSchaaf, Q.-Y. Shi, V. Schlegel, R. Schurhammer, P. A. Dowben, B. Doudin, L. Routaboul and P. Braunstein, New J. Chem., 2016, 40, 5782-5796.

6 (a) P. Braunstein, O. Siri, J.-P. Taquet, M.-M. Rohmer, M. Bénard and R. Welter, J. Am. Chem. Soc., 2003, 125, 12246-12256; (b) P. Braunstein, O. Siri and J. P. Taquet, 
WO 2004009534 A1, 2004; (c) J.-P. Taquet, O. Siri, P. Braunstein and R. Welter, Inorg. Chem., 2004, 43, 69446953; (d) Q.-Z. Yang, O. Siri and P. Braunstein, Chem.-Eur. J., 2005, 11, 7237-7246; (e) P. Braunstein, O. Siri, P. Steffanut, M. Winter and Q.-Z. Yang, C. R. Chim., 2006, 9, 1493-1499; (f) Q.-Z. Yang, A. Kermagoret, M. Agostinho, O. Siri and P. Braunstein, Organometallics, 2006, 25, 55185527; ( $g$ ) Q.-Z. Yang, O. Siri, H. Brisset and P. Braunstein, Tetrahedron Lett., 2006, 47, 5727-5731; (h) A. Ghisolfi, A. Waldvogel, L. Routaboul and P. Braunstein, Inorg. Chem., 2014, 53, 5515-5526; (i) M. Yuan, F. Weisser, B. Sarkar, A. Garci, P. Braunstein, L. Routaboul and B. Therrien, Organometallics, 2014, 33, 5043-5045.

7 For some recent articles see for examples: $(a)$ T. A. Darwish, Y. Tong, M. James, T. L. Hanley, Q. Peng and S. Ye, Langmuir, 2012, 28, 13852-13860; (b) F. M. Hoffmann, Y. S. Hoo, T. H. Cai, M. G. White and J. Hrbek, Surf. Sci., 2012, 606, 1906-1913; (c) M. Mucha, E. Kaletova, A. Kohutova, F. Scholz, E. S. Stensrud, I. Stibor, L. Pospisil, F. von Wrochem and J. Michl, J. Am. Chem. Soc., 2013, 135, 56695677; (d) T. Shimoaka, K. Rikiyama, Y. Katsumoto and T. Hasegawa, Anal. Bioanal. Chem., 2013, 405, 9411-9418; (e) K. Csanko, G. Kozma, L. Valkai, A. Kukovecz, Z. Konya, P. Sipos and I. Palinko, J. Mol. Struct., 2013, 1044, 32-38; (f) S. Kanata, T. Nishino, R. Makiura, S. Saiki and N. Hayashi, Anal. Sci., 2013, 29, 405-409; (g) M. Bouriga, M. M. Chehimi, C. Combellas, P. Decorse, F. Kanoufi, A. Deronzier and J. Pinson, Chem. Mater., 2013, 25, 90-97; (h) O. Buriez, F. I. Podvorica, A. Galtayries, E. Labbe, S. Top, A. Vessieres, G. Jaouen, C. Combellas and C. Amatore, J. Electroanal. Chem., 2013, 699, 21-27; (i) H. Jacob, K. Kathirvel, F. Petersen, T. Strunskus, A. Bannwarth, S. Meyer and F. Tuczek, Langmuir, 2013, 29, 8534-8543; (j) H.-X. Zhang, Y. Sasaki, M. Abe, Y. Zhang, S. Ye, M. Osawa and K. Uosaki, J. Electroanal. Chem., 2014, 714-715, 51-55; (k) W. Azzam, N. A. F. Al-Rawashdeh, N. Al-Refaie, O. Shekhah and A. Bashir, J. Phys. Chem. C, 2014, 118, 4846-4859; (l) S. Gam Derouich, C. Rinfray, G. Izzet, J. Pinson, J.-J. Gallet, F. Kanoufi, A. Proust and C. Combellas, Langmuir, 2014, 30, 2287-2296; (m) H. Jacob, S. Ulrich, U. Jung, S. Lemke, T. Rusch, C. Schuett, F. Petersen, T. Strunskus, O. Magnussen, R. Herges and F. Tuczek, Phys. Chem. Chem. Phys., 2014, 16, 22643-22650; (n) S. J. Jethwa, F. Grillo, H. A. Fruchtl, G. J. Simpson, M.-J. Treanor, R. Schaub, S. M. Francis, N. V. Richardson and R. A. Aitken, Chem. Commun., 2014, 50, 10140-10143; (o) E. de la Llave, S. E. Herrera, C. Adam, L. P. Mendez De Leo, E. J. Calvo and F. J. Williams, J. Chem. Phys., 2015, 143, 184703; ( $p$ ) J. Kestell, R. Abuflaha, M. Garvey and W. T. Tysoe, J. Phys. Chem. C, 2015, 119, 23042-23051; (q) A. I. Guttentag, T. Wachter, K. K. Barr, J. M. Abendroth, T.-B. Song, N. F. Sullivan, Y. Yang, D. L. Allara, M. Zharnikov and P. S. Weiss, J. Phys. Chem. C, 2016, 120, 26736-26746; (r) C. Partes, C. Yildirim, S. Schuster, M. Kind, J. W. Bats, M. Zharnikov and A. Terfort, Langmuir, 2016, 32, 11474-11484; (s) J. R. Henkie and P. A. Rowntree, Langmuir, 2016, 32, 11706-11716.

8 H. T. Le, P. C. Nam, V. L. Dao, T. Veszprémi and M. T. Nguyen, Mol. Phys., 2003, 101, 2347-2355.

9 (a) Kappa CCD Operation Manual, ed. B. V. Nonius, Delft, The Netherlands, 1997; (b) G. M. Sheldrick, SHELXL97, Program for the Refinement of Crystal Structures, University of Gottingen, Germany, 1997.

10 D. N. McIlroy, J. Zhang, P. A. Dowben and D. Heskett, Mater. Sci. Eng., A, 1996, 217/218, 64-68.

11 J. Choi, P. A. Dowben, S. Ducharme, V. M. Fridkin, S. P. Palto, N. Petukhova and S. G. Yudin, Phys. Lett. A, 1998, 249, 505511.

12 J. Xiao, L. G. Rosa, M. Poulsen, D.-Q. Feng, S. Reddy, J. M. Takacs, L. Cai, J. Zhang, S. Ducharme and P. A. Dowben, J. Phys.: Condens. Matter, 2006, 18, L155-L161. 13 J. Choi, C. N. Borca, P. A. Dowben, A. Bune, M. Poulsen, S. Pebley, S. Adenwalla, S. Ducharme, L. Robertson, V. M. Fridkin, S. P. Palto, N. Petukhova and S. G. Yudin, Phys. Rev. B: Condens. Matter Mater. Phys., 2000, 61, 57605770.

14 B. Xu, J. Choi, A. N. Caruso and P. A. Dowben, Appl. Phys. Lett., 2002, 80, 4342-4344.

15 M. E. Zandler and F. D'Souza, C. R. Chim., 2006, 9, 960-981. 16 (a) I. N. Yakovkin and P. A. Dowben, Surf. Rev. Lett., 2007, 14, 481-487; (b) F. Bechstedt, F. Fuchs and G. Kresse, Phys. Status Solidi B, 2009, 246, 1877-1892.

17 A. Sawicka, P. Skurski and J. Simons, Chem. Phys. Lett., 2002, 362, 527-533.

18 D. Delaere, P.-C. Nam and M. T. Nguyen, Chem. Phys. Lett., 2003, 382, 349-354.

19 T. Höltzl, T. Veszprémi and M. T. Nguyen, J. Phys. Org. Chem., 2005, 18, 1123-1131.

20 D. A. Kunkel, J. Hooper, S. Simpson, D. Miller, L. Routaboul, P. Braunstein, B. Doudin, P. Dowben, R. Skomski, E. Zurek and A. Enders, J. Chem. Phys., 2015, 142, 101921. 